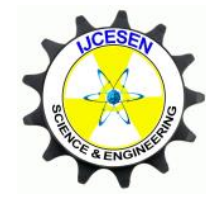

Copyright (C) IJCESEN
International Journal of Computational and

Experimental $\boldsymbol{S}$ cience and $\boldsymbol{E N g i n e e r i n g}$

(IJCESEN)

Vol. 5-No.3 (2019) pp. 151-153

http://dergipark.org.tr/ijcesen

Research Article

\title{
Recycling and Characterization of Metallic Chips Using Powder Metallurgy
}

\author{
Handan DEMİREL ${ }^{1}$, Aydın GÜNEŞ ${ }^{*}$, Ömer Sinan ŞAHİN² \\ ${ }^{1} 1$ Çankırı Karatekin University, Machine and Metal Tech. Department, Çankırı-Turkey \\ ${ }^{2 *}$ Abdullah Gul University, Mechanical Eng. Department, Kayseri-Turkey \\ ${ }^{3}$ Konya Technical University, Mechanical Eng. Department, Konya-Turkey \\ * Corresponding Author : aydingns@ @otmail.com \\ ORCID: 0000-0001-6930-1934
}

\section{$\underline{\text { Article Info: }}$}

DOI: $10.22399 /$ ijcesen.369722

Received : 21 December 2017

Accepted : 03 October 2019

\section{$\underline{\text { Keywords }}$}

Recycling

Metal chips

Sintering

\begin{abstract}
:
In this study, a new metal matrix composite material was produced by sintering from cast iron and bronze shavings made by recycling melting method. In the production of metal matrix composite material, $90 \% \mathrm{CuSn} 10$ as a matrix material and 10\% GGG40 cast iron as a reinforcement material were used. The chips having the same dimensions were mixed in a homogeneous mixture and pre-formed under a pressure of $1146 \mathrm{MPa}$ and then sintered at $875{ }^{\circ} \mathrm{C}$. The mechanical properties and porosity of the produced materials are characterized and the mechanical properties are compared with the mechanical properties of the bronze material in bulk state. According to the results, the mechanical properties of the material produced by the sintering method are very close to that of the bronze material in the bulk state.
\end{abstract}

\section{Introduction}

With the increasing world population and decreasing fossil resources, the need for alternative recycling resources has arisen in the industry. There has been increasing interest in other metal chip recycling methods besides the melting process in recent years. A few of them are recycling the chips with sintering and hot shaping [1-4]. Industrial recycling of metals is usually done by melting [5]. Another approach is to use 1 to $4 \mathrm{~mm}$ of chips. These dimensions are much more rough than the particle size used in conventional powder metallurgy [3-7]. According to another study, copper powders were combined with hot deformation of aluminum powders and a composite with improved mechanical properties was obtained [8]. In another study made with $\mathrm{Fe}, \mathrm{Cu}$ and Co powders subjected to sintering after cold pressing, it was seen that the $\mathrm{Cu}$ powders increased the density by closing the pores of the material. According to these and similar works, cast iron and bronze shavings were recycled by sintering after preshaping [3-7].

In this work, cold pressed metal matrix composite material was sintered at $875 \mathrm{C}$ with mixing of $90 \%$
Bronze and 10\% GGG40. The mechanical properties and microstructures of the obtained metal matrix composite material were investigated.

\section{Experimental Details 2.1.Material and Processing}

In the production of composite materials, $\mathrm{CuSn} 10$ was used as matrix material and GGG40 cast iron material was used as reinforcement material. The chemical contents of both components used are shown in Table 1. The materials were turned into chip under certain cutting conditions. The chips are then milled to a ball mill to achieve a more homogeneous structure.

Table 1 Chemical content of CuSn10 and GGG40

\begin{tabular}{|c|c|c|c|c|c|c|}
\hline Material & C & Si & Mn & S & Mg & P \\
\hline GGG40 & 3,4 & 2,5 & 0,13 & 0,01 & 0,046 & 0,08 \\
\hline Material & Cu & Sn & Zn & Pb & \multicolumn{1}{|}{} \\
\cline { 1 - 5 } CuSn10 & 88,2 & 9,3 & 1,35 & 0,01 & \multicolumn{1}{|c}{} \\
\cline { 1 - 4 }
\end{tabular}

Grinded chips are sieved in 1-2 mm sieves to obtain chips in the same form and size. The chips are weighed at a ratio of $90 \% \mathrm{CuSn} 10-10 \%$ GGG40 by 
weight with a precision of 0.001 gr. The chips were mixed with a conical mixer to obtain a homogeneous structure.

The mixed chips were placed in the compression test specimen mold and pre-formed by a single effective press. Compression was applied in two stages. the pressure was first applied to $955 \mathrm{MPa}$ at the same frequency, then the pressure was increased by $25 \%$ to $1146 \mathrm{MPa}$. Thus, compression samples having a diameter of $19 \mathrm{~mm}$ and a length of $42 \mathrm{~mm}$ were obtained (Figure 1-a).

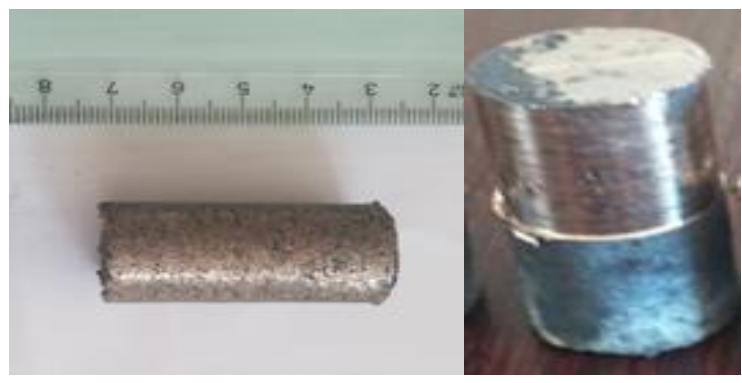

a)

b)

Figure 1 a) Compression sample b) Processed surface after sintering

The material was sintered in the ash furnace after being pre-shaped (Figure 1-b). The sintering process was carried out by cladding the raw samples with a seamless steel pipe with clad steel. During this time, some powdered graphite was thrown into the pipe. The reason for doing this is to minimize the oxidation at high temperature. Powder graphite is used to inhibit oxidation by binding oxygen remaining inside. During the sintering process, the materials were left at $875^{\circ} \mathrm{C}$ for 1 hour and then allowed to cool to room temperature. Figure 2 shows the sintering temperature profile. The sintered material was processed to have a diameter of $16 \mathrm{~mm}$ and a length of $32 \mathrm{~mm}$ and subjected to porosity and compression test. All experimental studies were repeated three times and averaged.

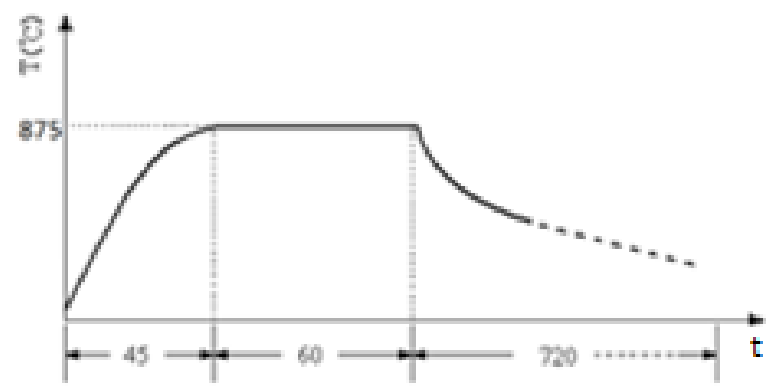

Figure 2. Sintering Temperature Profile
Compression tests were performed at room temperature in the Instron 8801 brand tensile testing machine. Compression test samples were broken by drawing at a feed rate of $2 \mathrm{~mm} / \mathrm{sec}$ according to ASTM (E9-89a) standard. Figure 3a shows the graph obtained after the pressing test. Stress, strain, force and elongation data were obtained in the results of the experiments. Also shown in figure $3 b$ is the material that breaks after the compression test.

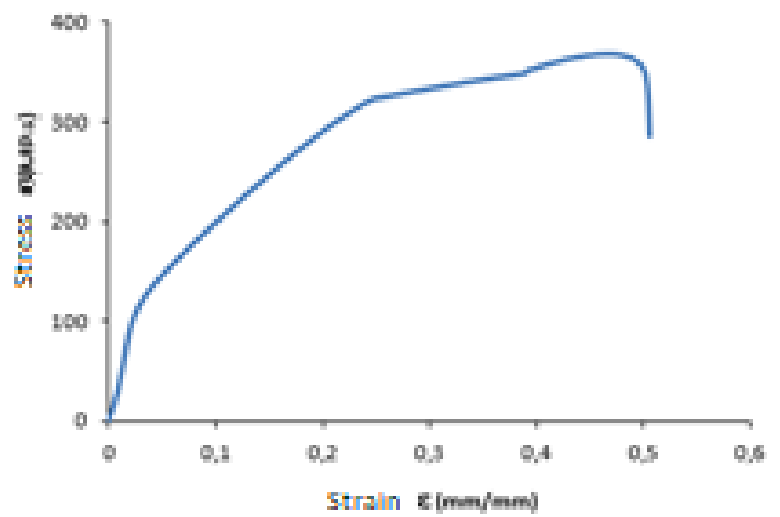

a)

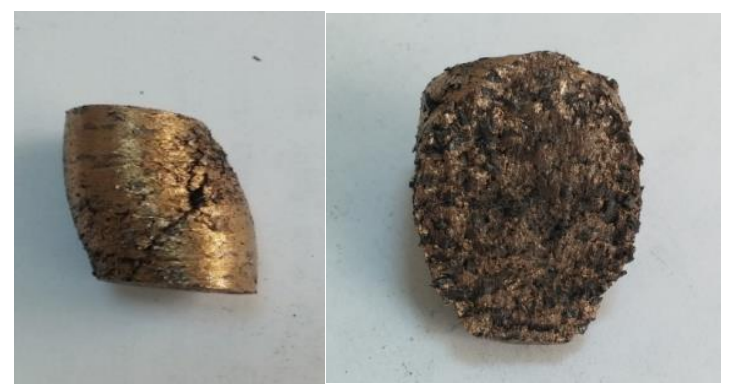

b)

Figure 3.a) Stress-Strain curve during the compression test b) broken sample after compression test

The densities of metal matrix composites were measured in Archimedean scale. Also the mechanical test values are given in Table 2. The processed specimens were first subjected to surface polishing in order to obtain optical microscope images. Microstructure images were taken on a reverse-metal microscope (Figure 4).

Table 2.Compression test results

\begin{tabular}{|c|c|c|c|c|c|c|c|}
\hline Material & $\begin{array}{c}\text { Compressire } \\
\text { Strenght }(\mathrm{MPa})\end{array}$ & $\begin{array}{c}\text { Resilience } \\
\left(\mathrm{J} / \mathrm{m}^{3}\right)\end{array}$ & $\begin{array}{c}\text { Toughness } \\
\left(\mathrm{J} / \mathrm{m}^{3}\right)\end{array}$ & $\begin{array}{c}\text { Epsilon Final } \\
(\mathrm{mm} / \mathrm{mm})\end{array}$ & $\begin{array}{l}\text { Relative Secant Mlod } \\
\left(\mathrm{S} / \mathrm{SS}_{0}\right)\end{array}$ & $\begin{array}{l}\text { Density } \\
\left(\mathrm{g} / \mathrm{cm}^{3}\right)\end{array}$ & $\begin{array}{c}\text { Porosity } \\
(\%)\end{array}$ \\
\hline $\begin{array}{l}\% 90 \text { CuSnilo- } \\
\% 10 \mathrm{GGG} 40\end{array}$ & $346,25 \pm 23,15$ & $0,53 \pm 0,01$ & $230,15 \pm 29,65$ & $0,5 \pm 0,02$ & $0,447 \pm 0,17$ & 7,163 & 16,222 \\
\hline Bullk CuSn10 & 491 & 9,84 & 360 & 0.93 & 0,61 & & \\
\hline
\end{tabular}

\section{Analysis Methods and Results}




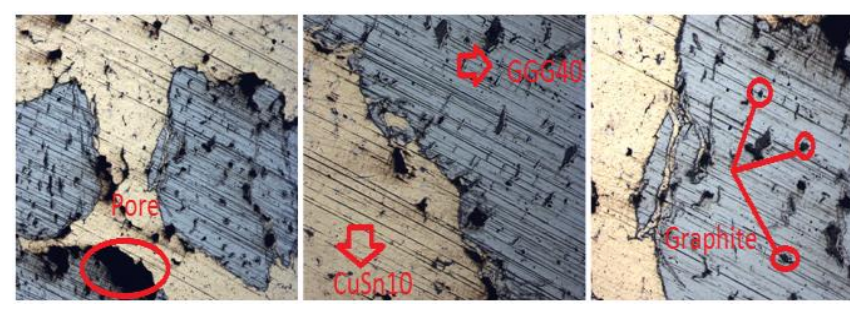

a) $875^{\circ} \mathrm{C}-50 \mathrm{x}$ b) $875^{\circ} \mathrm{C}-100 \mathrm{x}$ c) $875^{\circ} \mathrm{C}-100 \mathrm{x}$

Figure.4 Microstructure images

\section{Conclusions}

Cast iron and bronze metals can be recycled by sintering method after cold pressing instead of melting method. With this method, even though there is some attenuation in mechanical properties, this conversion can be achieved with a little material loss. The compression stress of the materials produced by this method could reach $70,5 \%$ of the compression stress of the bronze. This is an indication that the material has been recycled with this method. The toughness values of the produced materials reached $72 \%$ of the bronze toughness value in the mass state. This showed that the material could be recycled $72 \% .16 \%$ porosity of the produced composite materials will increase the oil absorption capacity. This feature makes the material available even when the bearing is not exposed to overpressure and the bearing is high speed. When the microstructure images of the composite material are examined, yellow parts show bronze and gray parts show cast iron. It is seen that the bronze shavings, which become semi-solid due to the effect of temperature, are joined together and become a whole by wrapping around the cast iron shavings. In addition, the pores and graphites in the structure draw attention.

\section{Acknowledgement}

This work has been funded by Tubitak (The scientific and technological research council of Turkey) under Grant number 113M141.

\section{References}

[1] S. Szezepanik, T. Sleboda, The influence of the hot deformation and heat treatment on the properties of $\mathrm{P} / \mathrm{M}$ AI-Cu composites, Journal of Materials Processing Technology, 60, 729-733, 1996.

[2]Abdullah Aslan, Aydin Güneş, Emin Salur, Ömer Sinan Şahin, Hakan Burak Karadağ, Ahmet Akdemir,
Mechanical Properties and Microstructure of Composites Produced by Recycling Metal Chips, International Journal of Minerals, Metallurgy, and Materials, 25 (9), 1070-1079, 2018.

[3]Abdullah Aslan, Emin Salur, Aydın Güneş, Ömer Sinan Şahin, Hakan Burak Karadağ, Ahmet Akdemir, The mechanical properties of composite materials recycled from waste metallic chips under different pressures", International Journal of Environmental Science and Technology, 16 (9), 5259-5266, 2019.

[4]Shuyan Wua, ZeshengJi, Tielei Zhanga, Microstructure and mechanical properties of AZ31B magnesium alloy recycled by solid-state process from different size chips, Journal of Materials Processing Technology 209, 5319-5324, 2009.

[5]Ömer Sinan Şahin, Aydin Güneş, Abdullah Aslan, Emin Salur, Hakan Burak Karadağ, Ahmet Akdemir, Low Velocity Impact Behavior of Porous Metal Matrix Composites Produced by Recycling of Bronze and Iron Chips, Ir. Journal of Science and Tech., Transactions of Mechanical Engineering, 43, 53-60, 2019

[6] Emin Salur, Abdullah Aslan, Mustafa Kuntoğlu, Aydın Güneş, Ömer Sinan Şahin, "Experimental Study and Analysis of Machinability Characteristics of Metal Matrix Composites During Drilling", Composites Part B: Engineering 166, 401-413, 2019.

[7] Abdullah Aslan, Emin Salur, Aydin Güneş, Ömer Sinan Şahin, Hakan Burak Karadağ, Ahmet Akdemir, Production And Mechanical Charecterization of Prismatic Shape Machine Element By Recycling of Bronze And Cast Iron Chips, Journal of the Faculty of Engineering and Architecture of Gazi University, 33 (3), 1013-1027, 2018.

[8] Maoliang Hu, Zesheng Ji, Xiaoyu Chen, Zhenkao Zhang Effect Of Chip Size On Mechanical Property And Microstructure Of Az91d Magnesium Alloy Prepared By Solid State Recycling, Materials Characterization 59(2008), 385-389. 